\title{
STUDY OF FATIGUE LIFE CALCULATION OF STEEL UNDER VARIOUS LOADING CONDITION
}

\author{
Anil Kumar \\ Asst.Prof (Krishna Engineering College) \\ Email-anil.kec609@gmail.com
}

Abhishek Pandey

Asso.Prof.(Krishna Engineering College)

Email-kec.abhishek@gmail.com
ABSTRACT - The aim of this work is to investigate the capability of experimental analysis, as a destructive tool testing, to characterize and quantify the fatigue behavior of material. This is achieved by studying the load parameter to the variations in material microstructure, are the main factor affecting fatigue life .Family of steel including the mild steel,stainless steel are used in experiment and including the non-ferrous material as aluminum as a case of presenting the load and variation in microstructure both.

Rotating bending test was performed on various standards fatigue specimen on rotating beam machine to correlate the parameter to the fatigue behavior .This enables the evaluation of the ability of fatigue tests to predict life of machine components.

\section{Keywords-Destructive tool, microstructure, rotating beam}

\section{INTRODUCTION}

\section{The Stress-Life Method}

To determine the strength of materials under action of fatigue loads, specimens are subjected to repeated or varying forces of specified magnitudes while the cycles or stress reversal are counted to destruction.

The most widely used fatigue-testing device is the R. R. Moore high-speed rotating-beam machine. This machines subject the specimen to pure bending (no transverse sheer) by means of weights. The specimen is very carefully machined and polished, with a final polishing in an axial direction to avoid circumferential scratches. Other fatigue-testing machines are available for applying fluctuating or reversed axial stresses, torsional stresses, or combined stresses to the test specimens[1].

To establish the fatigue strength of a material, quite a no. of tests are necessary because of the statistical nature of fatigue. For the rotatingbeam test, a constant bending load is applied, and the no. of revolution (stress reversals) of the beam required for failure is recorded. The first test is made at a stress that is somewhat under the ultimate strength of the material. The second test is made at stress that is less than that used in the first. This process is continued, and the results are plotted as an S-N Diagram.

To establish the fatigue strength of a material, quite a no. of tests are necessary because of the statistical nature of fatigue. For the rotatingbeam test, a constant Bending load is applied, and the no. of revolution (stress reversals) of the beam required for failure is recorded. The first test is made at a stress that is somewhat under the ultimate strength of the material. The second test is made at stress that is less than that used in the first. This process is continued, and the results are plotted as an S-N Diagram.

The chart may be plotted on semi-log paper or on log-log paper. In the case of ferrous materials and alloys, the graph becomes horizontal after the material has been stressed for a certain no. of cycles. The plotting on log paper emphasis the bend in the curve, which might not be apparent if the results were plotted by using Cartesian, coordinates. 
The ordinate of the S-N Diagram is called the fatigue strength $S_{\mathrm{f}}$; statement of this strength value must always be accompanied by a statement of the no. of cycles $\mathrm{N}$ to which it corresponds. S-N Diagrams can be determining either for a test specimen or for a actual mechanical elements. Even when the material of test specimen and that of the mechanical element are identical, there will be significant difference between the diagrams for the two [2].

In the case of the steels, a knee occurs in the graph, and beyond this knee failure will not occur, no matter how great the no. of cycles. The strength corresponding to the knee is Called the endurance limit $S_{e}$, or the fatigue limit. The graph never does become horizontal for nonferrous metals and alloys, and hence these materials do not have endurance limit. S-N curve for most common aluminium alloys excluding wrought alloys having a tensile strength below $38 \mathrm{kpsi}$. Since aluminium does not have an endurance limit, normally the fatigue strength $S_{\mathrm{f}}$ is reported at a specific no. of cycles $\mathrm{N}[1]$.

The body of knowledge available on fatigue failure from $\mathrm{N}=1$ to $\mathrm{N}=1000$ cycles is generally classified as low-cycles fatigue or finite - life region. High-cycles fatigue is infinite-life region, and then is concerned with failure corresponding to stress cycles greater than 1000 cycles.

As noted previously, it is always good engineering practice to conduct a testing program on the materials to be employed in design and manufacture. This, infect, is a requirement, not an option, in guarding against the possibility of a fatigue failure.

Because of this necessity for testing, it would really be unnecessary for us to proceed any further in the study of fatigue failure except for one important reason, the desired to know why fatigue failure occurs so that most effective method or methods can be used to improve fatigue strength. Thus our primary purpose in studying fatigue is to understand why failures occur so that we can guard against them in an optimum manner.

Experimental procedure-In this research we have done five experiment to analysing fatigue life. How fatigue life varies with Stress is shown in fig.

We have taken five specimen such as mild Steel with various quenching method (oil, water and brine), aluminium and stainless steel to conduct experiment.

Experiment conduct on rotating beam machine which was developed by R.R.Moore to know fatigue life is varies from load[4].

We have observed fatigue life decreases while increasing with load.in case of mild steel with quenching fatigue life decreases while in case of annealing and normalizing fatigue life increases [7].

\section{Experimental observation-1}

\begin{tabular}{|c|c|c|}
\hline \multicolumn{3}{|c|}{ Mild Steel Brine Quenched } \\
\hline S.NO & Stress (MN/sq.) & No. Of Cycles \\
\hline 1 & 41.4 & 6389 \\
\hline 2 & 31.05 & 14300 \\
\hline 3 & 20.7 & 22000 \\
\hline
\end{tabular}


ELK

Asia Pacific Journals

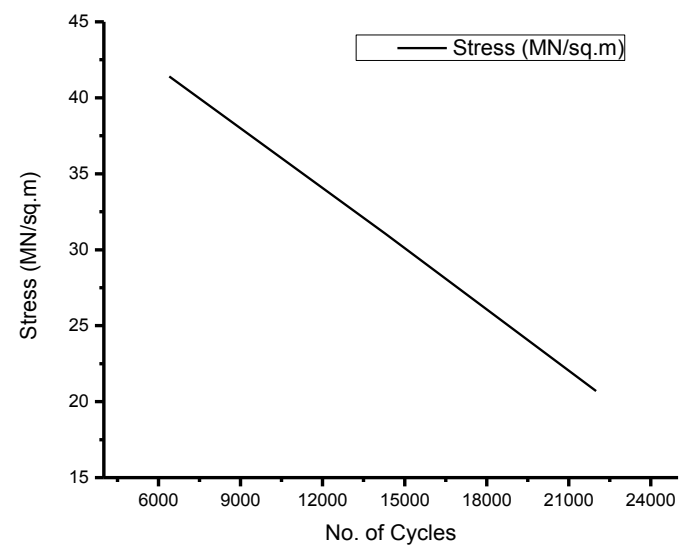

Experiment no-2

\begin{tabular}{|c|c|c|}
\hline \multicolumn{3}{|c|}{ Mild Steel water Quenched } \\
\hline S.NO & Stress (MN/sq.) & No. Of Cycles \\
\hline 1 & 41.4026 & 4448 \\
\hline 2 & 31.05 & 12200 \\
\hline 3 & 20.7 & 19998 \\
\hline
\end{tabular}

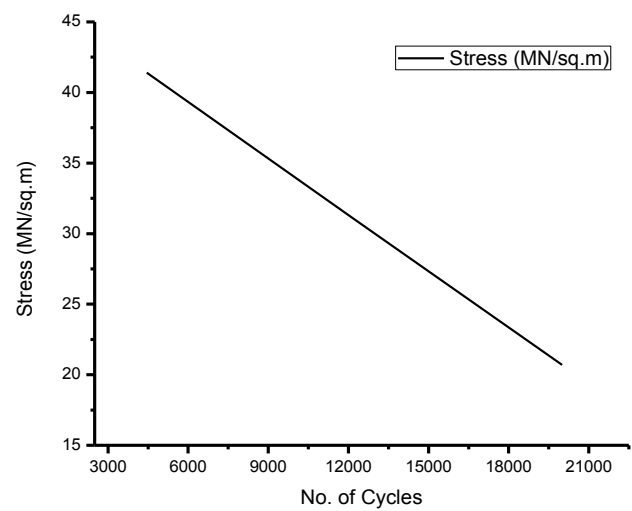

Experiment no-3 oil quench

\begin{tabular}{|c|c|c|}
\hline \multicolumn{3}{|c|}{ Mild Steel Oil Quenched } \\
\hline S.NO & Stress (MN/sq.) & No. Of Cycles \\
\hline 1 & 41.4 & 9800 \\
\hline 2 & 31.05 & 17650 \\
\hline 3 & 20.7 & 25325 \\
\hline
\end{tabular}

ELK Asia Pacific Journals - Special Issue ISBN: 978-81-930411-4-7

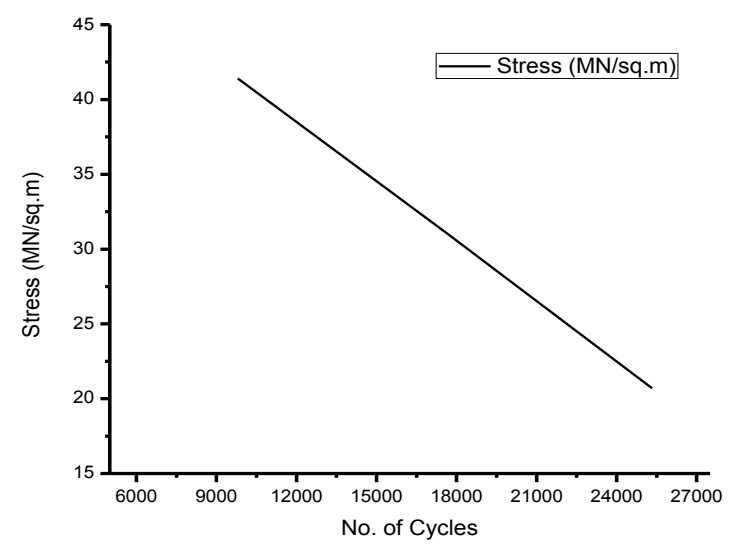

Experiment no-4

\begin{tabular}{|c|c|c|}
\hline \multicolumn{3}{|c|}{ Aluminium } \\
\hline S.NO & $\begin{array}{c}\text { Stress } \\
\text { (MN/sq.m) }\end{array}$ & No. Of Cycles \\
\hline 1 & 11.3506 & 1180 \\
\hline 2 & 12.93 & 908 \\
\hline 3 & 20.7 & 304 \\
\hline 4 & 31.05 & 110 \\
\hline
\end{tabular}

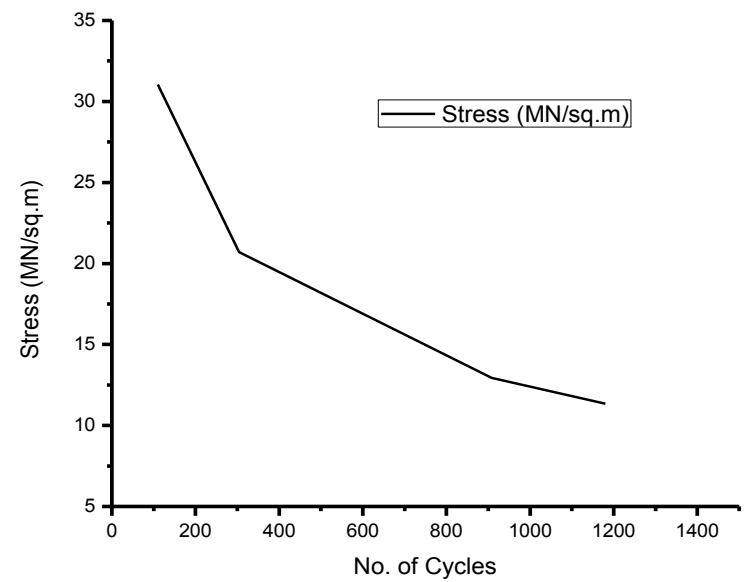

Experiment no-5

\begin{tabular}{|l|c|c|}
\hline \multicolumn{3}{|c|}{ Stainless steel } \\
\hline S.NO & Stress (MN/sq.m) & No. Of Cycles \\
\hline
\end{tabular}




\begin{tabular}{|l|c|c|}
1 & 41.4 & 64878 \\
\hline 2 & 51.75 & 11138 \\
\hline 3 & 62.103 & 1274 \\
\hline
\end{tabular}

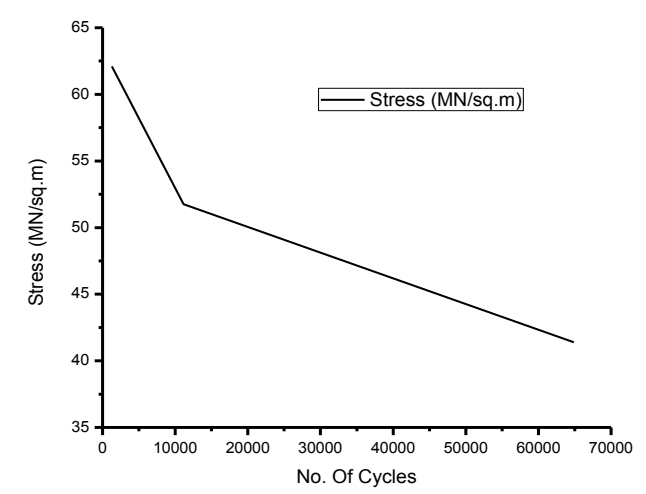

\section{CONCLUSION \&DISCUSSION-}

By practical readings and further calculations it is investigated that heat treated specimen had low values of fatigue life, which is due to increase in brittleness, hardness and low endurance strength. Quenching invariably sets up residual stresses in the specimen and resulting in cracks.

Generally the microstructure change takes place in the specimen which is also depicted in our experimental results. As above $725^{\circ} \mathrm{C}$, the mild steel mainly contains face centered cubic structure known as Austenite. The solid solubility of Austenite is much higher than that of with solid solubility of up to $2.11 \% \mathrm{C}$. Austenite is denser than ferrite and is ductile at elevated temperatures [6].

When the specimen is suddenly cooled, the Austenite instantaneously starts transforming into Martensite as because the cooling curve does not enter into the pearlite region. Martensitic is very hard and higher percentage of carbon.

The fatigue life of the specimen is reduced by increase in its brittleness and residual stresses.

\section{References-}

[1]. V. B. Bhandari - Machine Design- Tata McGraw Hill Publications.

[2]. Shigley-Machine Design- Tata McGraw Hill Publications.

[3]. V. Kazymyrovych *, 'J. Bergström, F. Thuvander2010 Local stresses and material damping in very high cycle fatigue" International Journal of Fatigue, vol 32 (2010) pg.1669-1674(Elsevier).).

[4]. Enrique Castillo,*, Alfonso FernandezCanteli c, Mar1 Luisa Ruiz-Ripoll " A general model for fatigue damage due to any stress history, International Journal of Fatigue vol30 (2008) pg.150-164(elsevier).

[5]. G. Socha " Experimental investigations of fatigue cracks nucleation, growth and coalescence in structural steel" International Journal of Fatigue vol. 25 (2003) pg.139-147. (Elsevier).

[6]. N. Damir, A. Elkhatib, G. Nassef "Prediction of fatigue life using model analysis for grey and ductile cast iron" International Journal of Fatigue vol.29 (2007) pg.499507(Elsevier).

[7].Seakjee lee \&young kook lee (2008); prediction of austenite grain growth during austenitization of low alloy steels material and design, vol29 pp1840-1844.

[8].Ashwin Suresh Pandit, -Theory of the Pearlite Transformation in Steels\|, (2011). 